\title{
Epstein-Barr Virus-Infected Marmoset Cells Do Not Form Lymphomas in Mice with Severe Combined Immunodeficiency ${ }^{1}$
}

\author{
BEN Z. KATZ, BABAK SALIMI, URMIL SAINI, JAMES G. MCNAMARA, AND \\ RICHARD EISEN \\ Departments of Pediatrics and Pathology, Yale University School of Medicine, New Haven, \\ Connecticut 06510 [U.S., J.G.M., R.E.], and Children's Memorial Hospital, Chicago, Illinois \\ 60614 [B.Z.K., B.S.]
}

\begin{abstract}
EBV has been associated with several malignancies in humans. EBV can also infect marmoset B lymphocytes, which, as opposed to human B cells, are permissive for lytic Epstein-Barr viral replication. Mice with a severe combined immunodeficiency phenotype (SCID mice) are extremely susceptible to EBV-induced lymphomagenesis when inoculated with EBV-infected lymphocytes. We inoculated SCID mice with human and marmoset lymphoblastoid cells infected with the same EBV isolates. The marmoset cells never gave rise to lymphomas, even after the administration of acyclovir or an anti-natural killer cell antibody and observation periods of up to $16 \mathrm{wk}$. In con-
\end{abstract}

EBV is the etiologic agent of heterophile-positive infectious mononucleosis and has been associated with several malignancies, most notably Burkitt lymphoma. EBV usually establishes a latent infection in B lymphocytes. The B lymphocytes of certain primate species (marmosets), however, are also susceptible to infection with EBV. As opposed to human B lymphocytes, marmoset B cells are usually somewhat more permissive for lytic infection with EBV (1).

To study the relationship between EBV and Burkitt lymphoma, several groups inoculated EBV-infected marmoset lymphocytes into cotton-top marmosets and reported the development of lymphomas (2-4). However, because EBV-infected marmoset cells are more permissive for lytic EBV replication, it was not possible to determine whether it was the inoculated cells or newly immortalized marmoset lymphocytes that developed into

\footnotetext{
Received February 28, 1994; accepted May 16, 1994.

Correspondence: Ben Z. Katz, M.D., Division Infectious Diseases, The Children's Memorial Hospital, 2300 Children's Plaza, Chicago, IL 60614.

Supported in part by Grants BRSG S07 RR05443 and AI 22959 from the National Institutes of Health.

${ }^{1}$ Presented in part at the Society for Pediatric Research Annual Meeting, Baltimore, MD, May 7, 1992.
}

trast, the human lymphoblastoid cells nearly always gave rise to lymphomas within $8 \mathrm{wk}$. Furthermore, human lymphoblastoid cells genetically engineered to permit lytic EBV replication also readily formed tumors in the SCID mouse. Thus, in this system, it is the cellular milieu that is crucial in determining whether a given lymphoblastoid cell will give rise to a tumor, not the EBV isolate harbored by the cell or whether the virus is permitted to undergo lytic replication. (Pediatr Res 36: 456-460, 1994)

Abbreviations

SCID, severe combined immunodeficiency

tumors. Therefore, these experiments are difficult to interpret regarding the tumorigenic potential of the injected cells.

In 1982, Bosma et al. (5) described a mouse that lacked both T- and B-cell function, similar to what is seen in patients with SCID. These mice were later characterized as having an inability to correctly rearrange their antigenreceptor genes on B and T cells (6). In 1988, Mosier et al. (7), in attempting to reconstitute these mice with human $B$ and $T$ cells, reported the development of EBV-positive B-cell lymphomas in mice inoculated with peripheral blood lymphocytes from EBV-seropositive individuals. Several other groups have also reported similar findings (8-19). Mosier and colleagues have since extended their observations to show that the peripheral blood of some EBV-seropositive donors is more likely to form tumors in SCID mice than that of others (20). Because murine lymphocytes lack the EBV receptor, they are incapable of being infected with the virus (21). Thus, it is the inoculated human cells that go on to form a lymphoma in this system.

Several groups have also injected lymphoblastoid cells into SCID mice, characterized the lymphomas and lymphoproliferative disorders that developed in the animals, 
and compared these disorders to the tumors that arise in transplant recipients $(8,10,12-14,17,18,22)$. [The injection of lymphoblastoid cells into nude or immunologically normal mice does not usually give rise to tumors (23).] To investigate the effect of lytic EBV replication on the pathogenesis of EBV-associated lymphomas, we inoculated several marmoset lymphoblastoid cell lines into SCID mice and compared them with human lymphoblastoid cell lines carrying the same isolate of EBV.

\section{METHODS}

Experimental animals. SCID/SCID CB 17 mice and $\mathrm{bg} / \mathrm{bg}$ mice were obtained from an Immunological Mouse Unit breeder colony of the Howard Hughes Medical Institute at the Yale University School of Medicine or from Taconic Farms (Germantown, NY). The mice were housed in a pathogen-free environment, fed sterilized food and water, and manipulated under a biosafety hood. All animals were cared for by the Division of Animal Care. A protocol of the experiments described herein was approved by the Animal Care and Use Committee.

Each experimental group consisted of two to four mice. All mice were inoculated intraperitoneally in the right lower abdominal quadrant with $10^{6}-10^{7}$ EBVinfected cells and any reagents used (see below) beginning at about $6 \mathrm{wk}$ of age. All mice were examined at least biweekly by one of the investigators (B.Z.K., B.S., or J.G.M.).

All mice were killed using carbon dioxide and cervical dislocation and then necropsied either when a large mass was palpated in the abdomen or when the animal appeared moribund. In two instances, an animal was found dead and immediately necropsied. Usually due to one of these events, animals were necropsied within $4-8 \mathrm{wk}$ of inoculation. In one experiment, nine well-appearing mice were killed 6 wk after inoculation; in all other experiments, well-appearing animals were killed 1 mo after animals inoculated at the same time with other EBVinfected lymphocytes developed tumors. Thus, most well-appearing mice were kept for up to $13-16$ wk after inoculation before being killed and necropsied.

Tumor analysis. Processing of all tumors was begun immediately after necropsy. All material not immediately analyzed was frozen as solid pieces at $-70^{\circ} \mathrm{C}$ in the presence of freezing medium (RPMI with 20\% FCS, antibiotics, and $8 \%$ DMSO). At least one paraffinembedded tumor corresponding to each experimental group (as represented by a single row in Table 1) was subjected to standard hematoxylin and eosin histology and immunoperoxidase staining (24) for $\kappa$ and $\lambda$ light chains, L26 (CD20), LN1 (CDw75), LN2 (CD74), and T-cell markers [UCHL-1 (CD45)]. Some samples were stained for human keratin (AE 1-3; BoehringerMannheim, Indianapolis, IN). All specimens so processed were reviewed blindly by a hematopathologist (R.E.). Tumors were characterized as to type based on morphology on hematoxylin and eosin staining and the
Table 1. Lymphomas developing in SCID mice after inoculation of human and marmoset lymphoblastoid cell lines infected with the same EBV isolates

\begin{tabular}{lcc}
\hline $\begin{array}{c}\text { Cell line } \\
\text { inoculated }\end{array}$ & $\begin{array}{c}\text { No. of mice } \\
\text { inoculated }\end{array}$ & $\begin{array}{c}\text { No. of mice with } \\
\text { tumors at necropsy }\end{array}$ \\
\hline B95-8 & 11 & 0 \\
B95-8/ACV* & 3 & 0 \\
B95-8/ACV $\dagger$ & 3 & 0 \\
B95-8/asialo GM1 $\dagger$ & 3 & 0 \\
B95-8/NRS $\dagger$ & 3 & 0 \\
FF41 & 8 & 0 \\
FF41/ACV* & 3 & 0 \\
FF41/asialo GM1 $\dagger$ & 4 & 0 \\
FF41/NRS $\dagger$ & 4 & 0 \\
X50-7 & 8 & 8 \\
B4 (X50-7/WZhet) & 3 & 3 \\
B95-8/CB & 5 & $3 \ddagger$ \\
FF41/CB & 3 & 3 \\
B95-8 + X50-7 & 3 & 3 \\
FF41 + X50-7 & 4 & 3 \\
\hline
\end{tabular}

* A single dose of reagent was given at the time of inoculation of the lymphoblastoid cells.

† Reagent was given biweekly after the single dose given at the time of inoculation of the lymphoblastoid cells.

$\ddagger$ One of these tumors was EBV-negative (see text).

surface expression (or lack thereof) of immunoglobulin as detected by immunoperoxidase staining (24).

We probed for and analyzed the EBV within the tumors in three ways. First, total cellular DNA was extracted, digested with BamHI, electrophoresed on a $0.6 \%$ agarose gel, transferred to nitrocellulose, probed for EBV sequences, and compared with the EBV DNA from the cell line whence the tumor originated (25). Second, proteins were extracted from the tumor and immunoblotted with EBV sera known to recognize primarily either replicating $(\mathrm{Ch})$ or latent (RM) EBV antigens (26), by methods previously described (27). The EBV proteins from each tumor were also compared with those from the cell line whence they originated. Third, we sought to identify EBV-immortalized cells within tumors as follows: parts of each tumor were minced with a scalpel blade and needle and placed in a flask in the presence of complete medium and observed for the outgrowth of a cell line; usually outgrowth of EBV-immortalized cells occurred within a few weeks.

Cell lines. The lymphoblastoid (human and marmoset) cell lines used were B95-8 and FF41 (marmoset lines permissive for lytic viral replication, described in 1979 and 1981, respectively), X50-7 [a tightly latent human umbilical cord blood lymphocyte transformant reported in 1979 using the virus from B95-8 cells $(28,29)]$, B4 [X50-7 cells transfected under antibiotic (G418; GIBCO, Grand Island, NY) selection with the BamHI WZ het fragment of EBV DNA, which causes the normally latent X50-7 cells to undergo lytic viral replication (30)], and B95-8/CB and FF41/CB (recent cord blood transformants using the B95-8 and FF41 virus, respectively, that are latently infected with EBV).

Reagents used. Twenty $\mu \mathrm{L}$ of normal rabbit serum or the monospecific (polyclonal) rabbit antibody anti-asialo 
GM1 (Wako Pure Chemicals USA, Richmond, VA; 42 $\mathrm{mg} / \mathrm{mL}$ protein, immunofluorescence titer $1: 1000$ ), able to deplete mice of natural killer cells in vivo $(18,31)$, were used. The antisera were diluted to $0.5 \mathrm{~mL}$ with RPMI 1640 to which had been added $15 \%$ FCS and antibiotics (complete medium) and injected into some mice $1 \mathrm{~d}$ before their inoculation with B95-8 or FF41 cells. Inoculations were then continued twice a week for the duration of the experiment (Table 1).

One hundred $\mu \mathrm{M}$ acyclovir sodium were used to inhibit lytic EBV DNA replication and thus prevent late antigen expression in the injected B95-8 and FF41 cells, as previously described $(27,32)$. In addition, some mice were treated with $0.5 \mathrm{mg}$ of acyclovir in $0.5 \mathrm{~mL}$ of complete medium $(4 \mu \mathrm{M})$ at the time of inoculation, as previously described (33). In one experiment, the injections were continued twice weekly. [In our hands, $1 \mathrm{~d}$ of pretreatment with $100 \mu \mathrm{M}$ acyclovir halts most lytic EBV DNA replication and late antigen expression $(27,32)$.]

\section{RESULTS AND DISCUSSION}

Tumors were nearly always generated in the SCID mice after injection of $5 \times 10^{6}$ human lymphoblastoid cells (Tables 1 and 2). The tumors that developed resembled large cell, immunoblastic-type non-Hodgkin lymphomas (Fig. 1). Five $\times 10^{6}$ marmoset cells infected with the same virus isolates as were present in the human lymphoblastoid cells inoculated and that are permissive for lytic EBV replication never gave rise to tumors (Tables 1 and 2). Thus, in this system, the cellular background (human versus marmoset) appeared to be crucial in determining whether tumors would develop.

All tumors tested were EBV genome or antigen positive and reacted with antibodies to human B-cell surface antigens by immunoperoxidase staining (24) except for one (Table 1 and data not shown). As expected, DNA restriction fragments of and proteins expressed by the tumors nearly always mimicked those of the inoculated cell line (data not shown). The EBV-negative tumor, which did not stain with the panel of human markers used (data not shown), was located in the anterior mediastinum and was believed to represent an intrinsic tumor of the SCID mouse (34).

One explanation for the inability of EBV-infected marmoset lymphoblastoid cells to form tumors in SCID mice is that marmoset cells are more susceptible to immunosurveillance by the SCID mouse than human cells. However, this explanation seemed unlikely to us, for marmo-

Table 2. Comparison of lymphomas developing in SCID mice after inoculation of human or marmoset lymphoblastoid cells carrying the same EBV isolates

\begin{tabular}{lcc}
\hline $\begin{array}{c}\text { Type of cell line } \\
\text { inoculated }\end{array}$ & $\begin{array}{c}\text { No. of mice } \\
\text { inoculated }\end{array}$ & $\begin{array}{c}\text { No. of mice with EBV- } \\
\text { induced tumors at necropsy }\end{array}$ \\
\hline Marmoset & 42 & 0 \\
Human & 19 & 16 \\
Human + marmoset & 7 & 6 \\
\hline
\end{tabular}
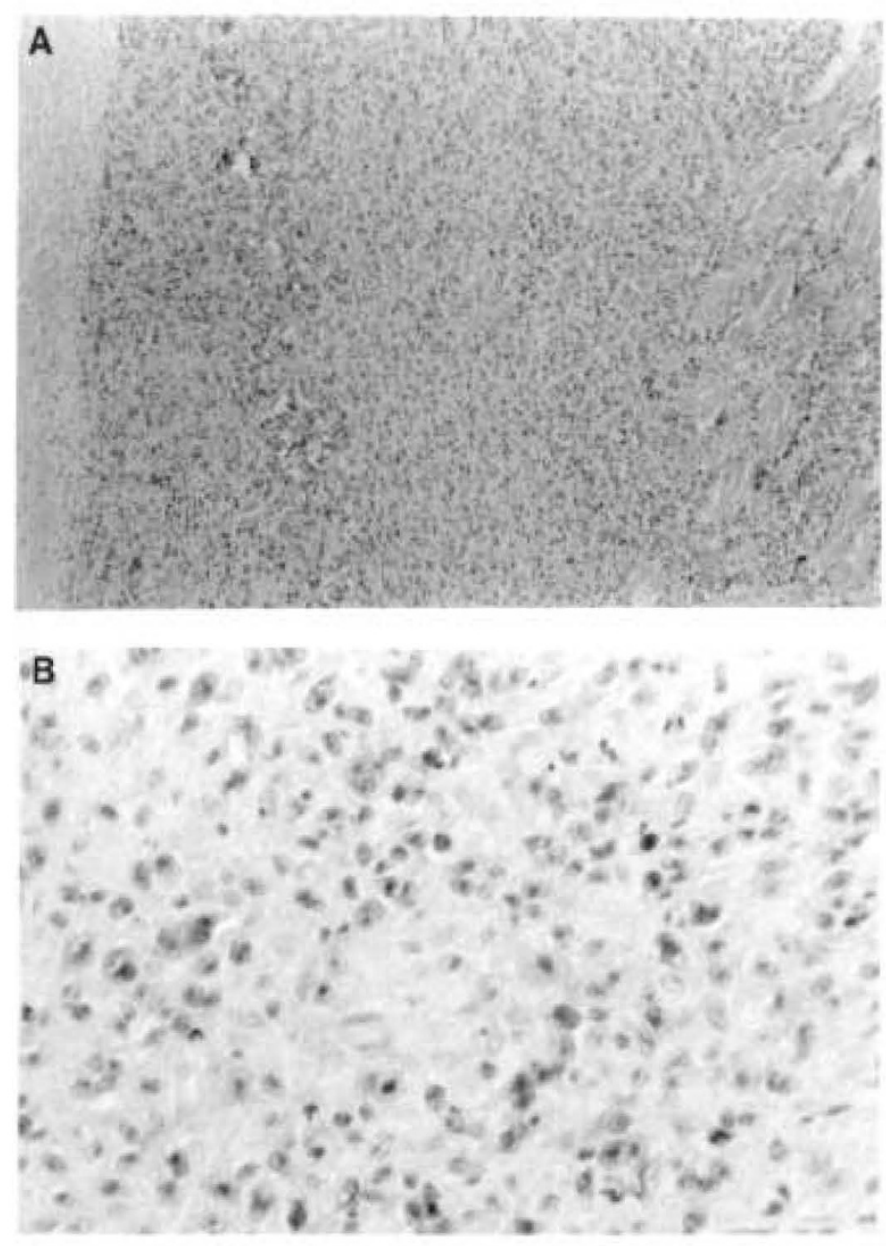

Figure 1. Histology of a large-cell, immunoblastic-like lymphoma that developed in a SCID mouse after intraperitoneal inoculation with X50-7 cells. $A$, This low-power view shows areas of necrosis (mainly on the left) and muscle invasion (on the right). $B$, This high-power view shows areas of pyknotic, dying cells, as well as large, immunoblastic-like lymphoma cells, many of which contain single, large nucleoli, eccentric nuclei, and a perinuclear halo (plasmacytoid features). Several mitoses are also visible.

set lymphocytes should be as easily recognized by the crippled immune system of the SCID mouse (presumably consisting mainly of natural killer cells, phagocytes, and their cytokines) as their phylogenetically related human counterparts. Nevertheless, we performed two experiments to test this hypothesis. First, we injected $10^{6}$ or $10^{7}$ FF41 cells into six natural killer cell-deficient (bg/bg) mice; none developed tumors. Thus, it appears that natural killer cells are not necessary for preventing tumor formation in the presence of normal $B$ and $T$ cells.

Second, we inoculated $5 \times 10^{6} \mathrm{EBV}$-infected marmoset cells into SCID mice that were pretreated with a rabbit antibody (anti-asialo GM1) known to be able to deplete mice of their natural killer cells (31). As a control, we pretreated a similar group of SCID mice with normal rabbit serum. No tumors were generated despite the additional immunosuppression (Table 1). [In parallel experiments, anti-asialo GM1 was able to promote the development of Burkitt lymphomas in SCID mice after 
inoculation of poorly lymphomagenic Burkitt lymphoma cell lines (35).] Thus, natural killer cells, even in the absence of $B$ and $T$ cells, are not preventing marmoset lymphocytes from forming tumors. Therefore, it appears that immunosurveillance is not playing the crucial role in limiting the outgrowth of the marmoset cells.

Perhaps the most obvious explanation for the lack of lymphoma development in the mice inoculated with EBV-infected marmoset cells is that marmoset lymphoblastoid cells are more permissive for lytic viral replication and consequently perish (1). To test this hypothesis, we performed two experiments. First, mice were inoculated with $5 \times 10^{6} \mathrm{~B} 4$ cells, which are latent human lymphoblastoid cells $(\mathrm{X} 50-7)$ genetically engineered to undergo lytic EBV replication. [The B4 cells were grown under antibiotic (G418) selection until the week before injection, because G418 is cytotoxic.] If lytic EBV infection somehow precluded lymphoma development, we would have expected no lymphomas to develop in the mice inoculated with the B4 cells. In contrast, six of seven animals inoculated with these cells developed tumors, as was also true when the latent parental line (X50-7) was inoculated (Table 1).

Second, we were unable to generate tumors after the inoculation of marmoset cells into SCID mice, despite pretreatment of both the cells and the mice with acyclovir, which inhibits lytic EBV DNA replication and late (lytic) antigen expression (Table 1). Therefore, it appears that lytic EBV replication does not play a crucial role in preventing lesion development in animals inoculated with EBV-infected marmoset lymphoblastoid cells.

A third possible explanation for the inability of EBVinfected marmoset cells to form tumors in SCID mice is that marmoset cells have a requirement for a growth factor not present in the SCID mice. The explanation that we favor, however, is that there is an inherent inability of marmoset lymphocytes to engraft onto the SCID mouse and cause lymphomas, perhaps due to the secretion of a particular lymphokine or to some difference in the cell surface of the marmoset lymphocyte. To test the first of these suppositions, we injected $5 \times 10^{6}$ marmoset and human lymphoblastoid cells simultaneously into the same mouse; lesions arose in six of seven instances (Tables 1 and 2). Where they were distinguishable by restriction analysis, the EBV DNA of the resulting tumors resembled the restriction pattern of the injected human cell line, not the marmoset line (data not shown). Regarding the latter supposition, the expression of cell surface markers is known to differ between human and simian lymphocytes and lymphoblastoid cells (36-38). If there is an inherent inability of marmoset cells to engraft onto the SCID mice, one might expect the same to be true of marmoset lymphoma cells themselves $(2,4)$. If this turns out to be the case, perhaps future molecular biologic manipulation of marmoset lymphocytes, lymphoblastoid cells, or lymphoma cells will allow the determination of what it is about the marmoset cells that prevents them from engrafting in SCID mice.
Acknowledgments. The authors thank George Miller, M.D., for helpful discussions and G. Terwilliger, J. Wroblewski, and J. Hernandez for expert assistance with necropsies.

\section{REFERENCES}

1. Miller G 1990 Epstein-Barr virus: biology, pathogenesis and medical aspects. In: Fields BN, Knipe DM, Chanock RM, Melnick JL, Roizman B, Shope RE (eds) Virology, 2nd Ed. Raven Press, New York, pp 1921-1958

2. Miller G, Shope T, Coope D, Waters L, Pagano J, Bornkamm GW, Henle W 1977 Lymphoma in cotton-top marmosets after innoculation with EpsteinBarr virus: tumor incidence, histologic spectrum, antibody responses, demonstration of viral DNA, and characterization of viruses. J Exp Med 145:948967

3. Rabin H, Neubauer RH, Hopkins RF III, Levy BM 1977 Characterization of lymphoid cell lines established from multiple Epstein-Barr virus (EBV)induced lymphomas in a cotton-topped marmoset. Int J Cancer 20:44-50

4. Johnson DR, Wolfe LG, Levan G, Klein G, Ernberg I, Aman P 1983 Epstein-Barr virus (EBV)-induced lymphoproliferative disease in cottontopped marmosets. Int J Cancer 31:91-97

5. Bosma GC, Custer RP, Bosma MJ 1983 A severe combined immunodeficiency mutation in the mouse. Nature 301:527-530

6. Schuler W, Weiler IJ, Schuler A, Phillips RA, Rosenberg N, Mak TW, Kearney JF, Perry RP, Bosma MJ 1986 Rearrangement of antigen receptor genes is defective in mice with severe combined immune deficiency. Cell 46:963-972

7. Mosier DE, Gulizia RJ, Baird SM, Wilson DB 1988 Transfer of a functional immune system to mice with severe combined immunodeficiency. Nature 335:256-259

8. Cannon MJ, Pisa P, Fox RI, Cooper RN 1990 Epstein-Barr virus induces aggressive lymphoproliferative disorders of human B cell origin in SCID/hu chimeric mice. J Clin Invest 85:1333-1337

9. Okano M, Taguchi Y, Nakamine H, Pirrruccello SJ, Davis JR, Beisel KW, Kleveland KL, Sanger WG, Fordyce RR, Purtillo D 1990 Characterization of Epstein-Barr virus-induced lymphoproliferation derived from human peripheral blood mononuclear cells transferred to severe combined immunodeficient mice. Am J Pathol 137:517-522

10. Purtillo DT, Falk K, Pirruccello SJ, Nakamine H, Kleveland KL, Davis JR, Okano M, Taguchi Y, Sanger WG, Beisel KW 1991 SCID mouse model of Epstein-Barr virus-induced lymphomagenesis of immunodeficient humans. Int J Cancer 47:510-517

11. Rowe M, Young LS, Crocker J, Stokes H, Henderson S, Rickinson AB 1991 Epstein-Barr virus (EBV)-associated lymphoproliferative disease in the SCID mouse model: implications for the pathogenesis of EBV-positive lymphomas in man. J Exp Med 173:147-158

12. Ramqvist T, Noren L, Iwarsson K, Klein G 1991 Tumorigenicity of EBVcarrying lymphoblastoid cell lines (LCLs): distinctive grading in SCID mice. Int J Cancer 49:587-591

13. Ghetie MA, Richardson J, Tucker T, Jones D, Uhr JW, Vitetta ES 1990 Disseminated or localized growth of a human B cell tumor (Daudi) in SCID mice. Int J Cancer 45:481-485

14. Walter J, Moller P, Moldenhauer G, Schirrmacher V, Pawlita M, Wolf J 1992 Local growth of a Burkitt's lymphoma versus disseminated invasive growth of the autologous EBV-immortalized lymphoblastoid cells and their somatic cell hybrids in SCID mice. Int J Cancer 50:265-273

15. Thangavelu M, Snyder L, Anastasi J, Le Beau MM, Kirven M, Picchio G, Mosier DE, Rowley JD 1992 Cytogenetic characterization of B-cell lymphomas from severe combined immunodeficiency disease mice given injections of lymphocytes from Epstein-Barr virus-positive donors. Cancer Res 52:46784681

16. Boyle TJ, Tamburini M, Berend KR, Kizilbash AM, Borowitz MJ, Lyerly HK 1992 Human B-cell lymphoma in severe combined immunodeficiency mice after active infection with Epstein-Barr virus. Surgery 112:378-386

17. Cohen JI, Picchio GR, Mosier DE 1992 Epstein-Barr virus nuclear protein 2 is a critical determinant for tumor growth in SCID mice and for transformation in vitro. J Virol 66:7555-7559

18. Malkovska V, Cigel FK, Armstrong N, Storer B, Hong R 1992 Antilymphoma activity of human gamma/delta T-cells in mice with severe combined immune deficiency. Cancer Res 52:5610-5616

19. Nakamine H, Masih AS, Okano M, Taguchi Y, Pirruccello SJ, Davis JR, Mahloch ML, Beisel KW, Kleveland K, Sanger WG, Purtillo DT 1993 Characterization of clonality of Epstein-Barr virus-induced human B lymphoproliferative disease in mice with severe combined immunodeficiency. Am J Pathol 142:139-147

20. Picchio GR, Kobayashi R, Kiven M, Baird SM, Kipps TJ, Mosier DE 1992 Heterogeneity among Epstein-Barr virus-seropositive donors in the generation of immunoblastic B-cell lymphomas in SCID mice receiving human peripheral blood leukocyte grafts. Cancer Res 52:2468-2477

21. Volsky DJ, Klein G, Volsky B, Shapiro IM 1984 Production of infectious Epstein-Barr virus in mouse lymphocytes. Nature 293:399-401

22. Durandy A, Brousse N, Rozenberg F, De Saint Basile G, Fischer AM, Fischer A 1992 Control of human B cell tumor growth in severe combined 
immunodeficiency mice by monoclonal anti-B cell antibodies. J Clin Invest 90:945-952

23. Nilsson K, Giovanella BC, Stehlin JS, Klein G 1977 Tumorigenicity of human hematopoietic cell lines in athymic nude mice. Int J Cancer 19:337-344

24. Falini B, Taylor CR 1983 New developments in immunoperoxidase techniques and therapeutic applications. Arch Pathol Lab Med 107:105-117

25. Katz BZ, Andiman WA, Eastman R, Martin K, Miller G 1986 Infection with two genotypes of Epstein-Barr virus in an infant with AIDS and lymphoma of the central nervous system. J Infect Dis 153:601-604

26. Rowe DT, Farrell PJ, Miller G 1987 Novel nuclear antigens recognized by human sera in lymphocytes latently infected by Epstein-Barr virus. Virology 156:153-162

27. Katz BZ, Saini U 1992 Presence of the diffuse early antigen of Epstein-Barr virus in lymphomas and lymphoproliferative disorders. Am J Pathol 140:1247-1254

28. Wilson G, Miller G 1979 Recovery of Epstein-Barr virus from nonproducer neonatal human lymphoid cell transformants. Virology 95:351-358

29. Fischer DK, Miller G, Gradoville L, Heston L, Weststrate MW, Maris W, Wright J, Brandsma J, Summers WC 1981 Genome of a mononucleosis Epstein-Barr virus contains DNA fragments previously regarded to be unique to Burkitt's lymphoma isolates. Cell 24:543-553

30. Grogan E, Jenson H, Countryman J, Heston L, Gradoville L, Miller G 1987 Transfection of a rearranged viral DNA fragment, WZhet, stably converts latent Epstein-Barr viral infection to productive infection in lymphoid cells. Proc Natl Acad Sci USA 84:1332-1336

31. Habu S, Fukui H, Shimamura K, Kasai M, Nagai Y, Okumura K, Tamaoki N
1981 In vivo effects of anti-asialo G. M.1: 1. reduction of NK activity and enhancement of transplanted tumor growth in nude mice. J Immunol $127: 34-38$

32. Katz BZ, Raab-Traub N, Miller G 1989 Latent and replicating forms of Epstein-Barr virus DNA in lymphomas and lymphoproliferative disorders. J Infect Dis 160:589-598

33. Larsson PA, Johansson SL, Hirsch JM, Vahlne A 1989 Effects of acyclovir on Herpes simplex virus type I infection in mice treated with 12-Otetradecanoylphorbol 13-acetate. J Gen Virol 70:1773-1778

34. Custer RP, Bosma GC, Bosma MJ 1985 Severe combined immunodeficiency (SCID) in the mouse: pathology, reconstitution, neoplasms. Am J Pathol 120:464-477

35. Katz BZ, Salimi B, Saini U, McNamara JG, Eisen RN 1994 The role of natural killer cells in the pathogenesis of Epstein-Barr virus-associated Burkitt lymphoma in a SCID mouse model. Int J Oncol 4:225-229

36. Robinson JE, Andiman WA, Henderson E, Miller G 1977 Host-determined differences in expression of surface marker characteristics on human and simian lymphoblastoid cell lines transformed by Epstein-Barr virus. Proc Natl Acad Sci USA 74:749-753

37. Crawford DH, Janossy G, Hetherington CM, Francis GE, Edwards AJ, Hoffbrand AV, Prentice HG 1981 Immunologic characterization of hematopoetic cells in the common marmoset, rhesus monkey, and man. Transplantation 31:245-250

38. Neubauer RH, Levy R, Strnad BC, Rabin H 1981 Reactivity of monoclonal antibodies against human leukocyte antigens with lymphocytes of non-human primate origin. J Immunogenetics 1981:8:433-442 